\title{
Carcinoma of the lung in Lancashire coalminers
}

\author{
G B ROOKE, ${ }^{1}$ F G WARD,1,3 A N DEMPSEY, ${ }^{1}$ J B DOWLER, ${ }^{1}$ AND C J WHITAKER ${ }^{2}$
}

From the Pneumoconiosis Medical Panel, Manchester, UK

ABSTRACT The prevalence at death of carcinoma of the lung in miners and ex-miners has been compared in those with and without pneumoconiosis at necropsy. The prevalence of $11.4 \%$ in the group as a whole is no greater than that in the male population in North-west England. Carcinoma of the lung was present in $62(13.1 \%)$ of those without pneumoconiosis and in 52 $(9 \cdot 8 \%)$ of those with pneumoconiosis.

The mean age at death of those with pneumoconiosis was 71.3 years so that they cannot be said to have died before the age at which they would have developed carcinoma. Those with progressive massive fibrosis whose mean age at death was 72 years had the lowest prevalence of carcinoma of the lung at all ages- $8.4 \%$.

For reasons stated in the text this is inevitably a biased sample. The number of those without pneumoconiosis is probably lower than the true figure because the deaths of miners and ex-miners in whom there is no suspicion of lung disease may not have been reported to the coroner or to the pneumoconiosis medical panel.

There appears to be no positive link between carcinoma of the lung and pneumoconiosis. There is a surprisingly high number of smokers and ex-smokers among these miners, and this appears to have more relevance to the prevalence of carcinoma of the lung than does pneumoconiosis.

The purpose of this study was to investigate the prevalence at death of carcinoma of the lung in coalminers who have worked in the Lancashire coalfields and to relate this to pneumoconiosis by direct observation of the lungs at necropsy without reference to the cause of death as stated on the death certificate.

Most investigations into the prevalence of carcinoma of the lung in coalminers have been based on information obtained from death certificates and occupational statistics. Heasman (1962) has shown that the cause of death as stated on death certificates may underestimate the prevalence of carcinoma of the lung by 15 to $20 \%$. Liddell (1973) has shown the unreliability of occupational statistics in giving the correct occupational status of a miner, especially when he has done other work after leaving the mines. Kennaway and Kennaway (1953) and Goldman (1965) using death certification and occupational statistics for their information found a relatively high incidence of

\footnotetext{
${ }^{1}$ Pneumoconiosis Medical Panel, Manchester.

${ }^{2}$ Research associate, Department of Occupational Health, University of Manchester.

${ }^{3}$ Accredited university teacher, Department of Occupational Health, University of Manchester.
}

carcinoma of the lung in coalminers in the Northwestern Division of the National Coal Board (NCB).

Mooney (1975) using his own necropsy material found 42 cases of carcinoma of the lung in 300 necropsies on coalminers with pneumoconiosis in the St Helens area of Lancashire-a prevalence of $14 \%$.

The Manchester Pneumoconiosis Medical Panel's catchment area comprises nine out of the 11 collieries currently in the North-western Division of the NCB. The panel, as one of its functions, reports to the insurance officers of the Department of Health and Social Security on the contribution industrial lung disease may have made to causing or accelerating death. Deaths of miners and ex-miners are reported to the coroner because it is widely known that death benefit may be available to their dependants. The coroner's pathologist retains the thoracic organs for the panel's examination after his necropsy. Because of this unique availability of necropsy material we have undertaken the present study of the lungs of miners and ex-miners who died in 1974, 1975, and 1976. 
It must be accepted that several of those who died without relatives or who had no symptoms of chest diseases are not included in this survey. Inquiries through the pensions branch of the NCB and the National Union of Mineworkers have shown that there is no way of estimating the total number of miners and ex-miners who die in any one year so it has not been possible to check how accurately this survey represents the true total of those who died.

\section{Methods}

The opportunity has been taken to assess the amount of pneumoconiosis present at necropsy and the occurrence of carcinoma of the lung, regardless of the part that either may have played in causing death.

There were 1015 deaths of miners reported to this panel during the three years 1974-6. Twelve were rejected because they had only worked in mines outside the area or because of insufficient information leaving 1003 for analysis.

Simple pneumoconiosis was considered to be present when sparse-or more-palpable nodulation was found on macroscopic examination of slices of lung tissue.

Progressive massive fibrosis (PMF) or complicated pneumoconiosis was diagnosed when a fibrotic mass exceeded $3 \mathrm{~cm}$ in diameter.

The cases were divided into four groups: (1) those with both lung carcinoma and pneumoconiosis; (2) those with pneumoconiosis only; (3) those with lung carcinoma only, and (4) those with neither lung carcinoma nor pneumoconiosis.

Groups 1 and 2 were further sub-divided into those with simple pneumoconiosis and those with complicated pneumoconiosis (PMF).

\section{Smoking history}

Most of those in groups 1 and 2 had been examined in life on several occasions whereas most in groups 3 and 4 had either never been examined by the panel in life or only on one occasion when they were found not to be suffering from pneumoconiosis. For this reason the smoking histories were available for $84.6 \%$ of those in group 1 and for $82.6 \%$ of those in group 2 , but only for $32.3 \%$ of those in group 3 and $28.1 \%$ of those in group 4 . Although relatively few smoking histories were known for those in groups 3 and 4, the smoking habits of those that were known appeared to be similar to those of groups 1 and 2.

The Medical Research Council's smoking classification was used:
Heavy-15 or more cigarettes daily/more than three ounces of tobacco a week.

Moderate-11-14 cigarettes daily/up to three ounces of tobacco a week.

Light-1-10 cigarettes daily/up to two ounces of tobacco a week.

Non-smoker-One who has never smoked as much as one cigarette a day or one ounce of tobacco a month for as long as one year.

Anyone who had stopped smoking or reduced his tobacco consumption was put into the highest smoking category he had achieved.

\section{Statistical methods}

The numbers of deaths in the male population dying from carcinoma of the lung (ICD 162) and from all causes for the years 1974-6 in Northwest England were used for comparison. These figures were obtained from the Office of Population Censuses and Surveys (OPCS) (1977, 1978a, and $1978 \mathrm{~b}$ ). The mean proportion of deaths from carcinoma of the lung in this region for the years 1974-6, in each 10-year age group, was multiplied by the observed number of deaths of miners, from all causes, in this age group. The expected numbers in each age group were then added together to give the expected numbers of deaths from carcinoma of the lung for miners. The observed and expected figures were then compared using the $\chi^{2}$ test (table 1).

\section{Results}

Of the 1003 deaths analysed, $114(11 \cdot 4 \%)$ cases of carcinoma of the lung were found. Table 1 shows the observed and expected numbers of deaths from carcinoma of the lung. Only for the miners with no pneumoconiosis was there a significant excess of observed over expected deaths $(P<0.05)$ from carcinoma of the lung.

Table 1 Observed and expected number of deaths with carcinoma of the lung in miners with no, simple, and complicated pneumoconiosis

\begin{tabular}{lclll}
\hline & $\begin{array}{l}\text { Deaths } \\
\text { all causes }\end{array}$ & $\begin{array}{l}\text { Observed } \\
\text { deaths } \\
\text { lung } \\
\text { cancer }\end{array}$ & $\begin{array}{l}\text { Expected } \\
\text { deaths } \\
\text { lung } \\
\text { cancer }\end{array}$ & Significance \\
\hline $\begin{array}{l}\text { Simple } \\
\text { pneumoconiosis }\end{array}$ & 196 & 24 & 19.2 & ns \\
$\begin{array}{l}\text { Complicated } \\
\text { pneumoconiosis }\end{array}$ & 332 & 28 & 30.4 & ns \\
$\begin{array}{l}\text { (PMF) } \\
\text { No pneumoconiosis }\end{array}$ & 475 & 62 & 47.9 & P<0.05 \\
Total & 1003 & 114 & 97.5 & $\mathrm{~ns}$ \\
\hline
\end{tabular}


Table 2 Mean age at death of those with pneumoconiosis

\begin{tabular}{|c|c|c|c|c|c|c|c|c|}
\hline \multirow[t]{3}{*}{ Age at death } & \multicolumn{4}{|l|}{ Groups } & \multicolumn{4}{|l|}{ Totals } \\
\hline & \multicolumn{2}{|l|}{$I$} & \multicolumn{2}{|l|}{2} & \multirow[t]{2}{*}{1 and 2} & \multirow{2}{*}{$\begin{array}{l}l \\
(a)+(b)\end{array}$} & \multirow{2}{*}{$\begin{array}{l}1 \text { and } 2 \\
(a)+(a)\end{array}$} & \multirow{2}{*}{$\begin{array}{l}1 \text { and } 2 \\
(b)+(b)\end{array}$} \\
\hline & $\begin{array}{l}\text { (a) } \\
\text { Simple }\end{array}$ & $\begin{array}{l}\text { (b) } \\
\text { Complicated } \\
(P M F)\end{array}$ & $\begin{array}{l}(a) \\
\text { Simple }\end{array}$ & $\begin{array}{l}\text { (b) } \\
\text { Complicated } \\
(P M F)\end{array}$ & & & & \\
\hline $45-54$ & 1 & 1 & 2 & 3 & 7 & 2 & 3 & 4 \\
\hline $55-64$ & 4 & 3 & 31 & 37 & 75 & 7 & 35 & 40 \\
\hline $65-74$ & 15 & 17 & 90 & 157 & 279 & 32 & 105 & 174 \\
\hline $75+$ & 4 & 7 & 49 & 107 & 167 & 11 & 53 & 114 \\
\hline Total & 24 & 28 & 172 & 304 & 528 & 52 & 196 & 332 \\
\hline Mean age at death & $69 \cdot 3$ & $71 \cdot 5$ & $70 \cdot 2$ & $72 \cdot 0$ & $71 \cdot 3$ & $70 \cdot 5$ & $70 \cdot 1$ & 71.98 \\
\hline
\end{tabular}

Pneumoconiosis was present in 528 of the whole group; of these $196(37 \cdot 1 \%)$ had simple pneumoconiosis as defined earlier and $332(62.9 \%)$ had PMF.

There were 475 without pneumoconiosis of whom carcinoma of the lung was found in 62 $(13 \cdot 1 \%)$. Of those with pneumoconiosis, $52(9 \cdot 8 \%)$ had carcinoma of the lung, $24(12 \%)$ with simple pneumoconiosis, and $28(8.4 \%)$ with PMF.

The mean age at death of all those with pneumoconiosis was 71.3 years, PMF 72 , and with carcinoma of the lung and pneumoconiosis 70.5 (table 2).

The figures for the mean age at death of those without pneumoconiosis have not been calculated because, as explained earlier, this is not considered to be a full sample of those miners and ex-miners who died without symptoms or signs of chest disease.

The smoking history of $573(57 \cdot 1 \%)$ was known $-526(91.8 \%)$ of these had smoked. The smoking histories of a high proportion of those with pneumoconiosis were known whereas a lower proportion of smoking histories was available for those without pneumoconiosis. Table 3 shows the distribution of miners in each of the four groups by smoking status. The proportion with pneumoconiosis (groups 1 and 2), when compared with all miners, was not significantly different in each smoking grade $\left(\chi^{2}=9.83, \mathrm{DF}=5,0.05<P<0.1\right)$.

When only those miners without carcinoma of the lung were considered, the proportion with pneumoconiosis (group 2) was not significantly different in each smoking grade $\left(\chi^{2}=9 \cdot 45, \mathrm{DF}=5\right.$, $0.05<P<0 \cdot 1)$. These two results show that the proportion with pneumoconiosis does not vary with smoking habits, both in those without carcinoma of the lung and in the whole group. The proportion with carcinoma of the lung (groups 1
Table 3 Smoking habits of subjects

\begin{tabular}{lrrrr}
\hline Smoking status & \multicolumn{2}{l}{ Groups } & & \\
\cline { 2 - 5 } & \multicolumn{1}{l}{1} & 2 & 3 & 4 \\
\hline Non-smoker & 2 & 39 & 0 & 6 \\
Stopped-light and moderate & 7 & 64 & 2 & 26 \\
Stopped-heavy & 5 & 51 & 5 & 13 \\
Smoker-light and moderate & 17 & 132 & 6 & 33 \\
Smoker-heavy & 4 & 39 & 3 & 20 \\
Reduced & 9 & 68 & 4 & 18 \\
Total known & 44 & 393 & 20 & 116 \\
Total unknown & 8 & 83 & 42 & 297 \\
Total & 52 & 476 & 62 & 413 \\
\hline
\end{tabular}

Groups 1-Carcinoma and pneumoconiosis. 2-Pneumoconiosis only. 3-Carcinoma only. 4-Neither.

and 3) was not significantly different in each smoking grade $\left(\chi^{2}=3.72, \mathrm{DF}=5,0.5<\mathrm{p}<0.7\right)$ but the numbers were small. Of the 64 cases of lung cancer whose smoking history was known, $62(96 \cdot 8 \%)$ had smoked.

\section{Discussion}

The prevalence of carcinoma of the lung at death in this series of coalminers and ex-miners was 114 out of a total of 1003 or $11.4 \%$. When compared with figures for male deaths in the population of the North West and Merseyside, supplied by the Office of Population Censuses and Surveys and by the Mersey Regional Health Authority (personal communication) for the years 1974-6, there is no significant excess of deaths from carcinoma of the lung among the miners and ex-miners in South Lancashire. No significant excess of lung carcinoma is found in those with pneumoconiosis.

At first sight a significant excess of carcinoma of the lung appears in those without pneumo- 
coniosis but this may be because, as explained earlier, the lungs of miners and ex-miners dying with no evidence of lung disease have not been sent to the panel. For this reason the total in this series of those without either pneumoconiosis or lung cancer may be artificially low. If this is so the figure of $11.4 \%$ for the overall prevalence of carcinoma of the lung in the group as a whole is an overestimate, as also is the prevalence of $13.1 \%$ in those without pneumoconiosis.

If Heasman's (1962) calculation is correct the official figures based on death certification will have underestimated the prevalence of lung cancer in the general population by 15 to $20 \%$, so that our findings based on direct examination of the lungs would show a still lower proportion of lung cancer prevalence in miners and ex-miners when compared with the male population as a whole. Histological typing of the tumours was not attempted in this series so that some of the cancers assumed to be primaries in the lung could possibly have been secondaries from tumours elsewhere in the body; if this were so the figure for carcinoma of the lung would be lower than stated.

It has been suggested (James, 1955; Goldman, 1965) that those with pneumoconiosis die before they reach the age at which carcinoma of the lung occurs; it is evident from the mean age at death of those with pneumoconiosis in this series that this is not so. It has also been stated that the diagnosis of carcinoma of the lung may be missed in the presence of PMF (James, 1955; Abbey Smith, 1959; Nealon, 1964), but these papers related to the radiographic diagnoses and not to necropsy examination. It is considered unlikely here because the lungs were examined by the coroner's pathologist as well as by two members of the pneumoconiosis medical panel.

It is arguable that our definition of pneumoconiosis does not cover the microscopic presence of fibrotic nodules or stellate areas of coal dust impregnation, but even if it is assumed that all the 1003 cases had pneumoconiosis the overall prevalence of carcinoma of the lung is still no greater than that in all male deaths in the area.

Smoking underground in coal mines is forbidden so that it might be assumed that miners smoke less than does the male population as a whole, but this is not so. It has been a widespread custom for miners to chew tobacco or take snuff underground; tradition has it that this would help them spit out the dust, and perhaps in this way they become addicted to nicotine. Of the 573 whose smoking history was known in this group, 91.8\% had been smokers. Several papers, summarised by Goldman (1965), have shown that a higher pro- portion of miners than non-miners smoked. Higgins et al (1956) in a survey at Leigh, Lancashire, found that $87.8 \%$ of a sample of miners smoked as opposed to $85.7 \%$ of a sample of nonmining men in the 55-64 age group. Higgins and Cochrane (1961) showed that $94.5 \%$ of miners and ex-miners in the Rhondda Fach had been smokers. Jacobsen (1976), studying a group of more than 11000 British miners, found that cigarette smokers had a nearly eight-fold excess of lung cancer deaths when compared with non-smoking miners. The carcinoma cases in our group in whom the smoking history was known do not show a significant difference in their smoking habits from those miners without carcinoma, but the numbers are relatively small.

It might be thought that carcinoma would be more commonly found in tissue that had previously been damaged by some process leading to scarring and therefore it should follow that PMF would be associated with an increased prevalence of lung cancer. Our results show that in fact there is a lower prevalence of carcinoma of the lung in cases of PMF. This was also noted by James (1955) and by Jacobsen (1976). This finding is of interest in view of Ashley's (1967) theory that some chronic dust diseases of the lung are protective against lung cancer.

Mooney (1975) claimed an association between pneumoconiosis and carcinoma of the lung. $\mathrm{He}$ is the coroner's pathologist for the St Helens area and, as such, refers cases of suspect industrial lung disease to the Manchester PMP. His cases came from within a ten-mile radius of $\mathrm{St}$ Helens. $\mathrm{He}$ based his findings on necropsy examination between 1967 and 1975 and considered microscopic evidence of pneumoconiosis to be significant. He found carcinoma of the lung in $14 \%$ of these miners. Smoking histories were not available, but he assumed that they would have been similar to those found by Higgins et al (1956) for a group of miners in the neighbouring town of Leigh. Jacobsen (1976) drew attention to a mine, now closed, in the North-western Division of the NCB, in which relatively high levels of carcinoma of the lung were found. This mine was at least 30 miles from St Helens and not within Mooney's catchment area, although some of the miners may have moved into his area after the pit's closure in 1971 . Both this mine and St Helens are within the Manchester PMP area, and miners and ex-miners who died in 1974-6 from both areas will have been included in our survey.

Figures supplied by the Mersey Regional Health Authority (personal communication) for 1975 and 1976 combined show the SMR for bronchial car- 
cinoma for all the male population in the St Helens and Knowsley area to be 121 and for the neighbouring Liverpool area to be 157. According to Heasman (1962) these figures will be 15 to $20 \%$ below the actual level that would have been found had necropsies been done in all cases. Against this background of an above-average death rate from carcinoma of the lung in the male population of the area, Mooney's figure of $14 \%$ lung cancer in miners reflects the trend in the area rather than an association with pneumoconiosis.

We are indebted to Dr J A G Carmichael, chief medical adviser and Dr R G B Williamson, principal medical officer of the Department of Health and Social Security for permission to publish the article, to Professor W R Lee and Dr E M Leck of the University of Manchester, to Dr P Oldham of the Pneumoconiosis Research Unit, Llandough Hospital, Penarth and to Dr W R Parkes, Pneumoconiosis Medical Panel, London, for their criticism and advice.

We are grateful to the Office of Population, Censuses and Surveys and the Mersey Regional Health Authority for supplying hitherto unpublished statistics, the staff of the Manchester Pneumoconiosis Medical Panel, and Mrs I Graven for their help.

\section{References}

Abbey Smith, R (1959). Lung Cancer in coalminers. British Journal of Industrial Medicine, 16, 318-323.

Ashley, D J B (1967). The distribution of lung cancer and bronchitis in England and Wales. British Journal of Cancer, 21, 243-259.

Goldman, K P (1965). Mortality of coalminers from carcinoma of the lung. British Journal of Industrial Medicine, 22, 72-77.

Heasman, M A (1962). Accuracy of death certification. Proceedings of the Royal Society of Medicine, 55, 733-740.

Higgins, I T T, Oldham, P P, Cochrane, A L, and Gilson, J C (1956). Respiratory symptoms and pulmonary disability in an industrial town. British Medical Journal, 2, 904-911.

Higgins, I T T, and Cochrane, A L (1961). Chronic respiratory disease in a random sample of men and women in the Rhondda Fach in 1958. British Journal of Industrial Medicine, 18, 93-102.

Jacobsen, M (1976). Dust exposure, lung disease and coalminer's mortality. $\mathrm{PhD}$ thesis, Edinburgh University.

James, W R L (1955). Primary lung cancer in South Wales coal workers with pneumoconiosis. British Journal of Industrial Medicine, 12, 87-91.

Kennaway, F L, and Kennaway, N M (1953). The incidence of cancer of the lung in coal miners in England and Wales. British Journal of Cancer, 7, 10-18.

Liddell, F D K (1973). Mortality of British coalminers in 1961. British Journal of Industrial Medicine, 30, $15-24$

Mooney, F S (1975). Coal worker's pneumoconiosis and carcinoma of the lung. Lancet, 1, 43.

Nealon, T F (1964). Carcinoma and anthracosilicosis. Archives of Environmental Health, 8, 882-885.

Office of Population Censuses and Surveys (1977). Mortality Statistics, 1974 series DHI, No 6. HMSO, London.

-(1978a). Mortality Statistics, 1975 series DHI, No 2.

-(1978b). Mortality Statistics, 1976 (unpublished).

Requests for reprints to $\mathrm{Dr} G$ B Rooke, Pneumoconiosis Medical Panel, Albert Bridge House West, Bridge Street, Manchester M60 9DH. 